\title{
Exploring social cognition in patients with apathy following acquired brain damage
}

\author{
Progress Njomboro ${ }^{1 *}$, Glyn W Humphreys ${ }^{2}$ and Shoumitro Deb ${ }^{3}$
}

\begin{abstract}
Background: Research on cognition in apathy has largely focused on executive functions. To the best of our knowledge, no studies have investigated the relationship between apathy symptoms and processes involved in social cognition. Apathy symptoms include attenuated emotional behaviour, low social engagement and social withdrawal, all of which may be linked to underlying socio-cognitive deficits.

Methods: We compared patients with brain damage who also had apathy symptoms against similar patients with brain damage but without apathy symptoms. Both patient groups were also compared against normal controls on key socio-cognitive measures involving moral reasoning, social awareness related to making judgements between normative and non-normative behaviour, Theory of Mind processing, and the perception of facial expressions of emotion. We also controlled for the likely effects of executive deficits and depressive symptoms on these comparisons.
\end{abstract}

Results: Our results indicated that patients with apathy were distinctively impaired in making moral reasoning decisions and in judging the social appropriateness of behaviour. Deficits in Theory of Mind and perception of facial expressions of emotion did not distinguish patients with apathy from those without apathy.

Conclusion: Our findings point to a possible socio-cognitive profile for apathy symptoms and provide initial insights into how socio-cognitive deficits in patients with apathy may affect social functioning.

Keywords: Apathy, Brain damage, Social cognition, Theory of mind, Emotion perception, Social awareness, Moral reasoning

\section{Background}

Over the past decade clinical observations and research have helped establish the position of apathy or lack of motivated activity as a common neuropsychiatric disorder following acquired brain damage, with important predictive relations to rehabilitation success [1-3]. Studies in the area have investigated the prevalence of apathy in various neuropsychiatric populations [4], its relationship with other disorders such as depression [5-8], and its association with executive processes involved in the cognitive control of goal-directed activity [9-14]. To the best of our knowledge no studies have investigated how apathy symptoms may relate to deficits in socio-cognitive domains such as social decision making related to moral reasoning and social awareness, Theory of Mind (ToM) judgements,

\footnotetext{
* Correspondence: Progress.Njomboro@uct.ac.za

${ }^{1}$ Department of Psychology, University of Cape Town, Rondebosch 7701, South Africa

Full list of author information is available at the end of the article
}

or the perception of facial expressions of emotion. The absence of studies in this area is striking when considered in the context of the functional impairments that patients with apathy show in their day-to-day lives. Behavioural problems characterised by social withdrawal, disinterest in social interactions, and deficits related to the experience and expression of emotions, form a significant part of the clinical picture in apathy [15-18].

Neurological models of motivated behaviour highlight the role of distinct frontal-subcortical circuits in human goal directed activity [11-13,19,20]. Damage to these circuits is thought to underlie apathy symptoms $[14,21]$, and these symptoms have been reported in patients with acquired brain damage involving both frontal and subcortical lesions. For instance, in one meta-analytical study [14] it was found that across five studies, an average of $61 \%$ of patients with focal frontal lesions and $41 \%$ of patients with subcortical damage presented with 
apathy symptoms. See also [22,23] for similar findings. Apathy is also often associated with anterior cingulate cortex (ACC) lesions [24-26]. Large or bilateral frontal and ACC lesions are known to cause even more severe apathy $[27,28]$. Imaging studies have found a relationship between apathy severity and bilateral atrophy of the medial and orbital frontal cortices, the ACC, temporal cortex and medial thalamic regions [18,29-32].

Damage to some of the frontal and subcortical brain areas implicated in apathy is often closely associated with social cognition deficits such as those involving moral judgements, feelings of regret, empathy, and embarrassment [33-36]. In some neuropsychiatric samples, functional and structural disruptions to neural mechanisms sub-serving socio-cognitive processes are thought to underlie significant behavioural aspects of brain pathology [37]. For example, impaired capacities to infer other people's beliefs and mental states have been reported in a wide range of neuropsychiatric disorders, including autism [38-40], frontal damage [41,42], schizophrenia [43-48], various types of dementias [49-51], antisocial personality disorder [52], and bipolar affective disorder [53]. It is likely that these socio-cognitive deficits make it difficult for patients to cope with and respond appropriately to their social world, resulting in social withdrawal and loss of interest in social life $[38,54]$. Such lack of interest and social withdrawal are some of the defining features of apathy $[17,55]$.

Some evidence on the neural substrates of social cognition, particularly on the role of emotion processing and its influences on human motivated behaviour has also been forthcoming [56-61]. Most of these studies suggest the involvement of subconscious emotional signals that help initiate and pre-bias goal-directed social behaviour towards adaptive choices [61-63]. It is possible that deficits in the mechanisms that generate these signals may underlie apathy related socio-cognitive dysfunction. The ventromedial prefrontal cortex is thought to play a crucial role in generating these signals [57], and has also been implicated in apathy [64]. Furthermore, patients with apathy show distinct deficits in their ability to initiate or sustain goal directed social interactions [13].

This study focuses on the relationship between apathy symptoms and social cognition. We hypothesized that patients with acquired brain damage who present with apathy symptoms would also present with significant impairments on a battery of socio-cognitive tasks designed to assess moral reasoning, social awareness, ToM, and emotion perception when compared to similar patients without apathy symptoms and also to neurologically intact participants. Our aim was to take patients with brain damage from a wide range of aetiologies in order to give a broad sample of possible relations between apathy and socio-cognitive processes. Measures of executive functioning and depressive symptoms were also taken in order to separate the possible effects of executive deficits and depression on social cognition from those of apathy symptoms. The literature suggests that executive deficits and depressive symptoms are associated with both apathy and some aspects of social cognition dysfunction $[10,11,65]$. We included 3 executive measures in order to accommodate cognitive deficits across patients. For instance, administering the Stroop test only would have meant dropping patients with language problems. In doing this we tried to obtain at least one executive function score for each of the participants. We however did not take these separate scores as interchangeable. We treated each of the executive function scores as a distinct covariate in our analyses.

\section{Methods}

\section{Participants}

Patients with brain damage were recruited from clinics and rehabilitation centres within the West Midlands region of England. All the patients were assessed at least 6 months post injury. In total 49 patients with neurological damage (see Table 1) and 56 neurologically intact adult controls participated in the study. Imaging results and lesion location data were available in 46 patients (see Table 2). Control participants were recruited from within the same area as patients through local adverts and were screened for neurological and psychiatric illnesses. Different controls took part on different tests. Table 3 gives the demographic characteristics of all participants (including controls) across the individual tests. All participants gave informed written consent. Ethics approval for the study was granted by the Birmingham and Solihull Research Ethics Committee.

\section{Materials and procedure}

\section{Apathy and depressive symptom measures}

The informant-rated Apathy Evaluation Scale (AES-I; [66]) was used to assess levels of apathy. The AES is the most widely used apathy scale in both research and clinical practice [67], and one of the few apathy scales with validated psychometric properties [66]. The scale is an

\begin{tabular}{|c|c|c|c|}
\hline Etiology & $N$ & $\begin{array}{l}\text { Sex } \\
M=\text { Male } \\
F=\text { Female }\end{array}$ & $\begin{array}{l}\text { Age } \\
\text { Mean \& Std Dev }\end{array}$ \\
\hline Cerebrovascular accident (CVA) & 24 & $M=15 ; F=9$ & $54.44(12.29)$ \\
\hline Head Injury & 14 & $M=11 ; F=3$ & $48.25(15.27)$ \\
\hline Anoxia & 5 & $M=5 ; F=0$ & $49.80(11.05)$ \\
\hline Herpes simplex encephalitis (HSE) & 6 & $M=5 ; F=1$ & $42.50(8.60)$ \\
\hline Total & 49 & $M=36 ; F=13$ & $48.75(11.80)$ \\
\hline
\end{tabular}


Table 2 Lesion location and apathy diagnosis

\begin{tabular}{lccc}
\hline Lesion & \multicolumn{2}{c}{ IAES - 41 score cut off } & \\
\cline { 2 - 3 } & Apathy & No apathy & Total \\
\hline Left parietal & 3 & 2 & 5 \\
Right parietal & 2 & 2 & 4 \\
Bilateral parietal & 0 & 1 & 1 \\
Left fronto-temporal & 3 & 4 & 7 \\
Right fronto-temporal & 5 & 2 & 7 \\
Bilateral fronto-temporal & 14 & 8 & 22 \\
\multicolumn{1}{c}{ Total $(N)$} & 27 & 19 & 46 \\
\hline
\end{tabular}

18-item instrument that assesses behavioural, emotional, and cognitive aspects of apathy. Each item on the scale, (e.g. s/he gets things done during the day) is rated on a scale of 1 (Not at all) to 4 ( $A$ lot). For a fuller description of this scale, its administration guidelines and psychometric properties see [66]. Patients' caregivers provided the ratings on the scale. A higher score on the scale indicates more apathy. An AES-1 score of 41 and above was taken as indicative of the presence of apathy, in line with the supplementary scoring guidelines obtained from the scale's authors. The level and presence of depressive symptoms were evaluated using the Beck Depression Inventory (BDI; [68]). We classified scores at or above the score of 11 as indicative of the presence of depression.

\begin{tabular}{|c|c|c|c|}
\hline Test & $\begin{array}{l}\text { Participant } \\
\text { type }\end{array}$ & $\begin{array}{l}\text { Sex } \\
M=\text { Male } \\
F=\text { Female }\end{array}$ & $\begin{array}{l}\text { Age } \\
\text { Mean \& Std } \\
\text { Dev }\end{array}$ \\
\hline Moral sense test & $\mathrm{AP}=15$ & $M=14 ; F=1$ & $52.83(15.03)$ \\
\hline \multirow[t]{2}{*}{$N=42$} & $N A=8$ & $M=7 ; F=1$ & $58.13(13.43)$ \\
\hline & $C=19$ & $M=10 ; F=9$ & $43.74(18.63)$ \\
\hline Social awareness test & $A P=13$ & $M=12 ; F=1$ & $53.46(13.31)$ \\
\hline \multirow[t]{2}{*}{$N=50$} & $N A=12$ & $M=7 ; F=5$ & $56.00(13.98)$ \\
\hline & $C=25$ & $M=12 ; F=13$ & $42.28(18.11)$ \\
\hline Reality Known & $A P=11$ & $M=9 ; F=2$ & $53.30(15.08)$ \\
\hline$N=20$ & $N A=9$ & $M=8 ; F=1$ & $55.33(14.37)$ \\
\hline Reality Unknown & $\mathrm{AP}=9$ & $M=8 ; F=1$ & $51.67(15.02)$ \\
\hline$N=21$ & $N A=12$ & $M=10 ; F=2$ & $55.25(14.67)$ \\
\hline Ekman 60 Test & $A P=21$ & $M=20 ; F=1$ & $58.91(12.14)$ \\
\hline \multirow[t]{2}{*}{$N=69$} & $N A=14$ & $M=9 ; F=5$ & $55.82(15.29)$ \\
\hline & $C=34$ & $M=20 ; F=14$ & $51.48(17.06)$ \\
\hline Emotion Hexagon Test & $A P=20$ & $M=19 ; F=1$ & $53.58(15.89)$ \\
\hline \multirow[t]{2}{*}{$N=60$} & $N A=13$ & $M=10 ; F=3$ & $57.8(14.55)$ \\
\hline & $C=27$ & $M=15 ; F=15$ & $54.74(17.89)$ \\
\hline
\end{tabular}

$A P$, Patients with Apathy; NA, Patients without Apathy; $C$, Healthy controls.

\section{Executive function tests}

The Brixton test

The Brixton Spatial Anticipation test [69] provided a measure of cognitive control for our patients. We chose this test because of its limited semantic loading, and also because research shows it is robust enough and sensitive to a number of executive processes, including set shifting and rule or feedback use in acquired brain damage $[69,70]$. The test consists of a series of pages in a booklet. Each page has the same basic design with ten circles in two rows of five each, one of which is coloured blue. The participants' task is to detect patterns in the sequence of the blue circle and then predict its position on subsequent pages. Further executive function measures were also obtained on the Stroop [71] and Hayling [69] tests.

\section{The Stroop test}

On the Stroop test participants name the colour of printed colour-words as fast as they can. A successful performance on the test requires the inhibition of the tendency to read the colour-words.

\section{The Hayling test}

On the Hayling test participants are read incomplete sentences that they should complete with a word that is not related in any way to the incomplete sentence. Successful performance on this test requires the inhibition of a pre-potent tendency to complete sentences.

\section{Social cognition tests Moral sense test}

The moral dilemma scenarios used to assess moral reasoning on the test were taken from the classical 'trolley dilemmas' used to explore intuitions about the permissibility of sacrificing the well-being of one person in order to save many others [72]. Participants were asked to rate on a 1-7 likert-type scale the moral permissibility of either intentionally harming one person in order to save many others (intended harm), or letting some foreseeable harm happen to one person in order to save many more (foreseen harm). The test consisted of 30 story vignettes made up of 10 control items, 10 intentional harm items, and 10 foreseeable harm items (see Additional file 1: Box 1).

\section{Social awareness test}

Dewey [73]'s Social Awareness Test (SAT) was used to assess participants' judgements of appropriateness of behaviour. The SAT consists of 9 short stories describing ordinary and unusual social interactions which participants have to judge by choosing (A) if they think the behaviour is "Fairly normal behaviour in that situation", (B) if they think the behaviour is "strange behaviour in 
that situation", (C) if they judge the behaviour as "very eccentric behaviour in that situation" and (D) if they think the behaviour described is "shocking behaviour in that situation" (see Additional file 2: Box 2).

\section{Theory of mind tests}

Two ToM tests were used: the Reality Known and the Reality Unknown tests. The tests comprised a series of carefully constructed non-verbal belief reasoning videos designed to control for deficits in memory, executive function and comprehension. See [74] for a full description of the tests. For example, in the Reality-Unknown test, a man placed an object in one of two identical boxes in full view of another female actor but without the participant seeing in which box the object was placed (participants did not know the reality about which box contained the object). The woman then left the room, and while away, the male actor swapped the two boxes. Upon returning, the woman pointed at one of the boxes. Locating the box containing the object then required participants to infer on the woman's false belief about the two boxes and to realize that the object was therefore in the box other than the one the woman pointed at. This ensured participants' attribution of false belief could not be disrupted by their own knowledge of the correct answer. To correctly infer the woman's false belief, participants did not need to inhibit their own self perspective. Deficits related to inhibiting one's self perspective are quite common in patients with brain damage, and have been shown to confound performance on false belief ToM tasks [75]. Inhibition control trials thus followed the same sequence as false belief trials, but instead of swapping the boxes, the man performed a visible transfer of the object from one box to the other in full view of the participant. Other trials in the two tests controlled for memory capacities. Working memory control trials followed the same sequence as false belief trials except that the woman indicated one of the boxes before leaving the room. This enabled the participant to infer the location of the object. In this case, inferring the correct location of the object did not require the attribution of a false belief, but as in the false-belief trial, participants had to remember that the location of the object changes when the boxes are swapped and had to maintain this information until a response was requested. The tasks' limited use of verbal language also controlled for problems related to semantic loading, which is a problem with most story-based false belief ToM tasks [76]. In the Reality Known test, the participants were aware of the location of the object.

\section{Emotion perception tests}

The Ekman 60 and the Emotion Hexagon tests from the Facial Expressions of Emotions Stimuli and Tests (FEEST)
CD-ROM [77] were used to assess perception of facial expressions of emotion. Both tests assess perception of the facial expressions of six basic emotional states of anger, disgust, fear, happiness, sadness, and surprise. Pictures of the emotional faces are presented on a computer screen.

On the Ekman 60 test each emotion is represented on 10 face images, giving a total of 60 images for the entire test. The faces on the emotion hexagon test are computermanipulated and morphed such that each emotion is presented in graded levels of difficulty and hence the emotions are comparatively more difficult to recognise than those on the Ekman 60 test. Each emotion is mixed or blended with another which it is most likely confused with, resulting in the following sequence of mixes; happiness-surprise-fear-sadness-disgust-anger. For example, the happiness-surprise continuum is morphed such that happiness would be blended with surprise (in ratios of $90 \%$ happiness with $10 \%$ surprise; $70 \%$ happiness with $30 \%$ surprise; $50 \%$ happiness with $50 \%$ surprise; $30 \%$ happiness with $70 \%$ surprise; $10 \%$ happiness with $90 \%$ surprise). The ends of this sequence (anger and happiness) join to form the emotion hexagon (see [77], for a detailed description of how the emotion hexagon test stimulus was made). The Emotion hexagon test has a total of 120 trials split into 4 blocks. In both the Ekman 60 and the Emotion hexagon tests, participants responded by using a mouse to click on one of the 6 emotion words (Anger, Disgust, Fear, Sadness, Surprise, and Happiness) presented at the bottom of the screen.

\section{Summary on tests}

Table 3 gives the participant composition on each of the tests used in this study. For a variety of reasons, ranging from patient drop out from the study to individual patients' specific neurocognitive impairments which made them unsuitable for some tests, it was not possible to assess all patients on every task. Normal participants were not assessed for depression and apathy symptoms because a history of psychiatric illness was part of our exclusion criteria. Neither did we test normal participants for executive deficits because we didn't have any practical or theoretical reason to expect them to present with these deficits.

\section{Data analysis}

Exploratory data analysis was done to test for normality of distribution and equality of variance. KolmogorovSmirnov (K-S) tests for normality of distribution and Levene's test for equality of variance where performed to ascertain whether data met assumptions for the use of parametric tests. Non-parametric test equivalents were performed on data that violated these assumptions. The correlation coefficient ( $r$ ) was used as a measure of effect size. 


\section{Results}

\section{Apathy and depression}

Twenty five patients (51\%) met the criteria for the presence of apathy in the absence of depression. The mean score for apathy in the group of patients with apathy symptoms was $50.96(\mathrm{SD}=9.64)$ and that for patients without apathy was $37.5(\mathrm{SD}=7.57)$. One patient $(2 \%)$ met the criteria for depression but not apathy. Two patients $(4.1 \%)$ met the criteria for the presence of both apathy and depression. As groups, the mean depression score for patients with apathy was 11.96 (SD = 7.97) and 11.83 (SD = 4.73) for patients without apathy. Twenty one patients (42.9\%) did not have either apathy or depression.

\section{Executive functions}

\section{Brixton test}

Brixton scores for patients with apathy symptoms $(\mathrm{M}=$ 27.72, $\mathrm{SE}=2.11$ ) were not significantly different from those of patients who had no significant apathy symptoms $(\mathrm{M}=24.31, \mathrm{SE}=1.98$; $\mathrm{t}(22)=1.14, \mathrm{p}>0.05$; which represented a small sized effect, $r=.27$. In subsequent analyses, we also included the Brixton score as a covariate because this test has been shown to demonstrate sensitivity to a variety of executive deficits, such as perseverative behaviour and deficits in feedback use.

\section{Hayling test}

No significant differences were found between patients with apathy $(\operatorname{Mdn}=20)$ and those without apathy $(\operatorname{Mdn}=11)$, $\mathrm{Z}=1.10$, ns, $\mathrm{r}=0.20$ on Section 1 of the Hayling test. Also, no significant difference were found between patients with apathy $(\operatorname{Mdn}=33)$ and those without apathy $(\operatorname{Mdn}=12)$, $\mathrm{Z}=.91$, ns, $\mathrm{r}=.17$ on Section 2 of the Hayling test.

\section{Stroop test}

Patients with apathy $(\mathrm{Mdn}=97)$ did not significantly differ from those without apathy on Section 1 of the stroop test (Mdn = 95.5), $\mathrm{Z}=0.552$, ns, $\mathrm{r}=.12$. T-test comparisons on Section 2 of the stroop test also showed no significant differences in performance between patients with apathy $(\mathrm{M}=50.13, \mathrm{SE}=8.74)$ and those without apathy $(\mathrm{M}=45.00, \mathrm{SE}=11.35 ; \mathrm{t}(21)=.35, \mathrm{p}>0.05$, which represented a small sized effect $\mathrm{r}=.08$.

\section{Social cognition \\ Moral sense test}

We excluded from analysis all subjects whose responses fell more than 2 standard deviations from the control mean on more than 2 of the 10 control scenarios because we felt such participants did not understand the stories. For this reason, data for 9 patients were excluded from analysis. Data for 2 of the normal participants were also excluded because they failed to complete the test. Table 4 shows the means and standard deviations
Table 4 Means and standard deviations for responses to 'Intended harm' and 'Foreseen harm' moral dilemmas of the Moral sense test

\begin{tabular}{|c|c|c|c|c|c|c|}
\hline \multirow[b]{2}{*}{ Harm } & \multicolumn{2}{|c|}{ Control $(n=17)$} & \multicolumn{2}{|c|}{ Apathy $(n=7)$} & \multicolumn{2}{|c|}{ No apathy $(n=7)$} \\
\hline & Mean & Std Dev & Mean & Std Dev & Mean & Std Dev \\
\hline Intended & 2.14 & 0.94 & 4.63 & 1.52 & 2.91 & 1.23 \\
\hline Foreseen & 3.06 & 0.85 & 4.63 & 1.30 & 3.82 & 1.41 \\
\hline
\end{tabular}

for the three participant groups on the MST foreseen and intended harm dimensions.

\section{Intended harm}

A one way ANOVA showed that the 3 participant groups differed on how they judged intentional harm $\mathrm{F}(2,28)=11.55, \mathrm{p}<0.001$. Tukey HSD post hoc tests revealed that patients with apathy judged that intentionally harming one person to save many more as more permissible $($ Mean $=4.63)$ than healthy controls $($ Mean $=2.14$, $\mathrm{p}<0.001$ ), and patients without apathy (Mean $=2.91$, $\mathrm{p}<0.05)$. There were no significant differences in judgements between healthy controls and patients without apathy $(\mathrm{p}>0.05)$. Including Brixton scores as a covariate while comparing patients with apathy and those without apathy's intentional harm scores showed no significant effects of the Brixton score on moral judgements, $F(1,11)=$ 2.17 , ns., and the differences in moral judgements between the 2 patient groups also remained significant, $\mathrm{F}(1,11)=$ $7.69, \mathrm{p}<0.05$. Including the BDI score as a covariate showed a borderline effect of depression and moral judgements $(F(1,11)=5.35, p=0.05)$ but the difference between moral judgements in patients with apathy and those without apathy remained significant $(\mathrm{F}(1,11)=11.23, \mathrm{p}<0.01)$.

\section{Foreseen harm}

Judgements on the foreseen harm dimension differed across the 3 participant groups, $\mathrm{F}(2,27)=6.82, \mathrm{p}<0.01$. Post hoc Tukey HSD tests showed no differences on judgements on the moral permissibility of allowing some foreseen harm to happen to one person in order to save others between patients with apathy $($ Mean $=4.90)$ and those without apathy (Mean $=3.82, \mathrm{p}>0.05)$. There were significant differences between healthy control participants $($ Mean $=3.06)$ and patients with apathy $(\mathrm{p}<0.01)$ but no significant differences between healthy controls and patients without apathy ( $\mathrm{p}>0.05)$. Including Brixton scores as a covariate while comparing patients with apathy against scores for those without apathy showed no effect of the Brixton score on moral judgements $(F(1,11)=2.91$, ns $)$ though the differences in moral judgements between patients with apathy and those without apathy became borderline significant $(\mathrm{F}(1,11)=4.27, \mathrm{p}<.01)$. There was no significant effect of the BDI score on moral judgements, $F(1,11)=1.25$, ns, and the difference 
between patients with apathy and those without apathy's foreseen harm judgements remained non-significant $\mathrm{F}(1,11)=2.98$, ns.

\section{Social awareness test}

We took "A" responses on the test to indicate that participants judged protagonists' behaviour as normative, while " $B$ ", "C", and " $D$ " responses indicated that participants judged the behaviour as a social norm violation. Healthy controls (see Table 3 ) provided normative data. Only items on which we obtained more than 95\% consensus $(\mathrm{p}<.05)$ from healthy controls were used for this analysis. This consensus was obtained on 12 out of the 23 SAT test items. On these 12 items more than $95 \%$ of the controls identified 5 behaviours as normal, and 7 as norm violations.

On the basis of our normative data, relatively fewer patients with apathy (84.6\%) correctly identified normal behaviour compared to those without apathy (91.7\%). Chi-square tests revealed that the percentage of those who correctly identified normative behaviour differed according to the presence of apathy symptoms $\left(x^{2}[3]=200\right.$, $\mathrm{p}<.001$ ). Based on the odds ratio, patients without apathy were 2.03 times more likely to correctly judge normal behaviour as normal than patients with apathy symptoms. Also, fewer patients with apathy (Mean $=78 \%$ ) correctly identified norm violations compared to those without apathy $(89.3 \%)$. Chi-square tests revealed that the percentage of those who correctly identified norm violations differed according to the presence of apathy symptoms $\left(x^{2}(3)=200, p<.001\right)$. Based on the odds ratio, patients without apathy were 2.28 times more likely to correctly identify social norm violations compared to patients with apathy.

When patients who took the SAT test were compared on executive functioning and depressive symptoms, there were no significant differences between those with apathy symptoms and those without apathy on the Brixton Spatial Anticipation test (apathy patients median = 27; non-apathy patients median $=21 ; U=40.5$, ns). There were also no significant differences in depressive symptoms levels on the BDI between patients with apathy $($ Median $=17)$ and those without apathy $($ Median $=11.5$; $\mathrm{U}=52.5$, ns). The significant differences in social awareness on the SAT cannot therefore be explained by differences in executive function or depressive symptoms levels.

\section{Theory of mind tests}

We did not include a normal control group for the ToM tests used in this study because a pilot study on the tests showed that people without neurological damage performed at ceiling level. See also [74]. We tested the effects of apathy symptoms on ToM by comparing performance between patients with and without apathy on the false belief score and on control items for working memory, inhibition, true belief and the filler scores for both the reality known and reality unknown tasks.

\section{Reality known test}

A one way MANOVA comparing patients with and without apathy on false belief, working memory, anti-strategy, and filler scores on the Reality known test revealed non-significant main effects for apathy, Wilk's $\lambda=.853$, $\mathrm{F}(4,15)=.646, \mathrm{p}>.05$ partial eta squared .147 . Power to detect the effect was .166 (see Table 5 for the full results).

\section{Reality unknown test}

A one way Manova comparing patients with and without apathy on false belief, working memory, inhibition, true belief (comprehension) and filler scores of the Reality unknown test revealed non-significant effects for apathy, Wilk's $\lambda=.969,(4,16)=.128, \mathrm{p}>.05$ partial eta squared .031. Power to detect the effect was .07 (see Table 5 for the full results).

\section{Emotion Perception tests \\ Ekman 60 test}

Kruskal-Wallis tests comparing the total number of correctly identified facial expressions of emotions across the three participant groups showed a significant effect of participant group on emotion recognition $\mathrm{H}(2)=34.82$, $\mathrm{p}<0.001$. Mann-Whitney post hoc tests with a Bonferroni correction of 0.0167 significance level showed that the healthy controls $(M d n=51)$ correctly recognised more facial expressions of emotions compared to both patients with apathy $(M d n=41 ; \mathrm{U}=52.5, \mathrm{p}<0.001, \mathrm{r}=-.71)$ and those without apathy $(M d n=51 ; \mathrm{U}=51.5, \mathrm{p}<0.001$, $\mathrm{r}=-.61$ ). The difference between scores for patients with apathy and those without apathy was not significant ( $\mathrm{U}=$ 140.5 , ns, $\mathrm{r}=-.04)$. Comparisons on each individual emotion across the three groups also yielded the same pattern

Table 5 Statistical comparisons on Theory of mind scores for patients with apathy versus those without apathy

\begin{tabular}{llll}
\hline & Apathy & No apathy & Manova statistic \\
\hline Reality Known Task & 9 & 8 & \\
False Belief task & & 11 & \\
Memory Control & 12 & 12 & \\
Anti-strategy control & 12 & 12 & \\
Filler trials & 12 & Mean & \\
Reality Unknown Task & Mean & 7.42 & $P>.05$ \\
False Belief task & 7.56 & 9.83 & \\
Working Memory & 10.11 & 12 & \\
Inhibition Control & 12 & 9.83 & \\
True Belief & 10.11 & 11.5 & \\
Fillers & 12 &
\end{tabular}


of results. Due to the loss of power likely to result from these multiple comparisons across individual emotion categories, a Bonferroni correction was applied (see Table 6 for the full results).

\section{Emotion hexagon test}

Kruskal Wallis tests showed an overall reliable difference between the three groups of participants in their ability to recognise emotions, $H(2)=26.11, p<0.001$. Post Hoc Mann Whitney tests showed that healthy control participants $(M d n=110)$ recognised significantly more expressions compared to both patients with apathy $(M d n=87$; $\mathrm{U}=45, \mathrm{p}<0.01, \mathrm{r}=-.71)$ and without $(M d n=75 ; \mathrm{U}=57.5$, $\mathrm{p}<0.01, \mathrm{r}=-.54)$. There were no significant differences between patients with apathy and those without apathy $(\mathrm{U}=127$, ns, $\mathrm{r}=-.02)$. Table 6 shows the full results across individual emotion categories. To address possible power slippages due to multiple test comparisons, a Bonferroni correction was applied.

\section{Discussion \\ Overview}

Our results provide new evidence that apathy symptoms in patients with acquired brain damage are associated with making impaired social judgements. For instance, patients with apathy tended to judge that intentionally harming one person (intended harm) in order to save many more (as in pushing a bulky man onto a runaway trolley in order to stop it from hitting 5 others) was morally permissible, while patients without apathy and healthy controls both tended to judge such means-to-an-end intentional harm as not permissible. On the other hand, where harm to one person was not directly intended, but a foreseeable side effect of diverting the harm from five people (foreseen harm), moral judgements for both patients with apathy and those without apathy were not significantly different. Furthermore, patients with apathy failed to recognise as many instances of norm violations as patients without apathy on the SAT, while also misjudging more normal behaviours as norm violations. The majority of our patients with apathy symptoms also had frontal lesions, confirming findings from other studies on the association between frontal damage and both socio-cognitive deficits and apathy symptoms (see discussion below). Performance scores on social cognition measures for emotion perception (Ekman 60 and Emotion hexagon tests), and ToM failed to separate patients with apathy from those without apathy symptoms, though the patients with apathy tended to perform worse. In these cases, the patients as a whole were reliably worse than controls.

\section{Apathy and moral reasoning}

The current data on our Moral sense test that highlights changes in moral reasoning in patients with apathy may be accounted for in a variety of ways. For example, recent research suggests a crucial role of emotional influences on moral reasoning. It has been demonstrated that in moral dilemmas where harm is both intentional and direct, an emotionally aversive reaction is generated that makes people disapprove of the act $[64,78]$. Valdesolo and DeSteno [64] further found that inducing positive emotions (to counteract the aversive emotional responses involved in intentional harm dilemmas) made normal participants more likely to approve the harm. More evidence for the role of emotional processes in social behaviour has been documented by Bechara et al. [56], who demonstrated that patients with prefrontal damage my fail to generate emotion signals that help bias behaviour towards adaptive social acts. See also [61,79]. The responses of the patients with apathy here then may reflect a lack of emotional engagement. The most salient feature of apathy involves attenuated emotional behaviour [17].

In support of the above suggestions, Mendez, Anderson, and Shapira [80] found that emotionally blunted patients with frontotemporal dementia were also disproportionately more likely to give utilitarian responses in response to moral dilemmas similar to those used in this study. It should also be noted that damage to brain areas thought to subserve this emotional input, such as the anterior cingulate cortex and the ventro-medial pre-frontal cortex (VMPC) [81,82] have also been consistently associated with the presence of apathy $[2,83,84]$. Our current results are consistent with this explanation since the majority of those patients who had apathy symptoms and also malperformed on the moral sense test (57.1\%) had bilateral prefrontal lesions. In this context, the evidence suggests that an underlying affective processing deficit might underlie apathy symptoms. Also in support of this position, Levy and Dubois [21] argue that lesions to the orbital-medial prefrontal regions can disrupt affective processing of the emotional signals that are responsible not only for directing ongoing or forthcoming behavior, but that also play a role in decoding the context and motivational value of behavioural events. Such disruptions then make it difficult for patients to elaborate or formulate action plans, leading to apathetic behaviour.

Our study is however limited in the extent to which it can attribute poor performance on the moral dilemmas to emotional deficits such as those proposed by Damasio et al. [82] since measures of emotional responding were not concurrently taken. It is also important to note that other researchers working with different clinical samples have explained the type of moral reasoning deficits found in our patients in terms of impaired theory of mind processing for moral judgements [85]. However ToM performance did not distinguish patients with apathy from those without apathy in this study (see below). 
Table 6 Statistical comparisons between patients with apathy, patients without apathy, and normal controls on tests for the perception of facial expressions of emotion

\begin{tabular}{|c|c|c|}
\hline \multirow[t]{2}{*}{ Emotion } & \multirow{2}{*}{$\begin{array}{l}\text { Kruskal-Walis } \\
\text { test result }\end{array}$} & \multirow{2}{*}{$\begin{array}{l}\text { Post hoc comparisons } \\
\text { Bonferroni } \\
\text { correction }=0.0167\end{array}$} \\
\hline & & \\
\hline \multirow[t]{3}{*}{ EKMAN 60} & $\begin{array}{l}H(2)=34.82 \\
p<0.001\end{array}$ & $\begin{array}{l}\text { C vs } A \cup=52.5, p<0.001 \\
r=-.71^{*}\end{array}$ \\
\hline & & $\begin{array}{l}\text { C vs NA U = 51.5, } p<0.001 \\
r=-.61^{*}\end{array}$ \\
\hline & & $\begin{array}{l}\text { A vs NA } U=140.5, n s, r= \\
-.04\end{array}$ \\
\hline \multirow[t]{3}{*}{ Anger } & $\begin{array}{l}H(2)=17.95 \\
p<0.001\end{array}$ & $\begin{array}{l}\text { C vs A U }=165, p<0.001 \\
r=-.46^{*}\end{array}$ \\
\hline & & $\begin{array}{l}\text { C vs NA U }=84, p<0.001 \\
r=-.51^{*}\end{array}$ \\
\hline & & A vs NA $U=134, n s, r=-.08$ \\
\hline \multirow[t]{3}{*}{ Disgust } & $\begin{array}{l}H(2)=22.71 \\
p<0.001\end{array}$ & $\begin{array}{l}\text { C vs A U }=127.5, p<0.001 \\
r=-.55^{*}\end{array}$ \\
\hline & & $\begin{array}{l}\text { C vs NA U }=78.5, p<0.001 \\
r=-.51^{*}\end{array}$ \\
\hline & & $\begin{array}{l}\text { A vs } N A \cup=125.5, n s, \\
r=-.12\end{array}$ \\
\hline \multirow[t]{3}{*}{ Fear } & $\begin{array}{l}H(2)=16.78 \\
p<0.001\end{array}$ & $\begin{array}{l}\text { C vs A U }=143.5, p<0.001 \\
r=-.5^{*}\end{array}$ \\
\hline & & $\begin{array}{l}\text { C vs NA U }=170, p<0.01 \\
r=-.46^{*}\end{array}$ \\
\hline & & $A$ vs $N A U=126, n s, r=-.12$ \\
\hline \multirow[t]{3}{*}{ Happiness } & $\begin{array}{l}H(2)=9.21 \\
p<0.05\end{array}$ & $\begin{array}{l}\text { C vs } A \cup=289, p<0.01 \\
r=-.35^{*}\end{array}$ \\
\hline & & $\begin{array}{l}\text { C vs NA U }=170, p<0.01 \\
r=-.46^{*}\end{array}$ \\
\hline & & A vs $N A U=136, n s, r=-.09$ \\
\hline \multirow[t]{3}{*}{ Sadness } & $\begin{array}{l}H(2)=15,47 \\
p<0.001\end{array}$ & $\begin{array}{l}\text { C vs A U }=213, p=0.01 \\
r=-.35^{*}\end{array}$ \\
\hline & & $\begin{array}{l}\text { C vs NA U }=87.5, p<0.001 \\
r=-.51^{*}\end{array}$ \\
\hline & & A vs $N A \cup=92.5, n s, r=.32$ \\
\hline
\end{tabular}

\begin{tabular}{|c|c|c|}
\hline \multirow[t]{3}{*}{ Surprise } & \multirow[t]{3}{*}{$\begin{array}{l}H(2)=9.27 \\
p<0.01\end{array}$} & $\begin{array}{l}\text { C vs } A \cup=208.5, p<0.01 \\
r=-.35^{*}\end{array}$ \\
\hline & & $\begin{array}{l}\text { C vs NA U }=137, p<0.01 \\
r=-.34^{*}\end{array}$ \\
\hline & & $\begin{array}{l}\text { A vs NA } U=146, n s, r= \\
-.001\end{array}$ \\
\hline \multirow[t]{3}{*}{$\begin{array}{l}\text { EMOTION } \\
\text { HEXAGON }\end{array}$} & \multirow[t]{3}{*}{$\begin{array}{l}H(2)=26.11 \\
p<0.001\end{array}$} & $\begin{array}{l}\text { C vs } A \cup=45, p<0.01 \\
r=-.71^{*}\end{array}$ \\
\hline & & $\begin{array}{l}\text { C vs NA U }=57.5, p<0.01 \\
r=-.54^{*}\end{array}$ \\
\hline & & A vs $N A U=127, n s, r=-.02$ \\
\hline \multirow[t]{3}{*}{ Anger } & \multirow[t]{3}{*}{$\begin{array}{l}H(2)=26.11, p< \\
0.001\end{array}$} & $\begin{array}{l}\text { C vs } A \cup=97, p<0.01 \\
r=-.55^{*}\end{array}$ \\
\hline & & $\begin{array}{l}\text { C vs NA U }=71, p<0.01 \\
r=-.48^{*}\end{array}$ \\
\hline & & $A$ vs $N A U=130, n s, r=0$ \\
\hline
\end{tabular}

Table 6 Statistical comparisons between patients with apathy, patients without apathy, and normal controls on tests for the perception of facial expressions of emotion (Continued)

\begin{tabular}{|c|c|c|}
\hline \multirow[t]{3}{*}{ Disgust } & \multirow{3}{*}{$\begin{array}{l}\mathrm{H}(2)=8.22 \\
\mathrm{p}<0.05\end{array}$} & C vs $A \cup=116, n s, r=-.09$ \\
\hline & & $\begin{array}{l}\text { C vs NA U }=92.5, p=0.015 \\
r=-.39^{*}\end{array}$ \\
\hline & & $A$ vs $N A U=116, n s, r=-.09$ \\
\hline \multirow[t]{3}{*}{ Fear } & \multirow[t]{3}{*}{$\begin{array}{l}H(2)=23.06 \\
p<0.001\end{array}$} & $\begin{array}{l}\text { C vs A U }=67, p<0.01, \\
r=-.64^{*}\end{array}$ \\
\hline & & $\begin{array}{l}\text { C vs NA U }=59.5, p<0.01 \\
r=-.53^{*}\end{array}$ \\
\hline & & $A$ vs $N A U=108, n s, r=-.14$ \\
\hline \multirow[t]{3}{*}{ Happiness } & \multirow[t]{3}{*}{$\begin{array}{l}H(2)=9.38 \\
p<0.01\end{array}$} & $\begin{array}{l}\text { C vs } A \cup=160, p<0.01 \\
r=-.44^{*}\end{array}$ \\
\hline & & $C$ vs NA $U=143, n s, r=-.22$ \\
\hline & & $A$ vs $N A U=95, n s, r=-.25$ \\
\hline \multirow[t]{3}{*}{ Sadness } & \multirow[t]{3}{*}{$\begin{array}{l}H(2)=27.39 \\
p<0.001\end{array}$} & $\begin{array}{l}\text { C vs } A \cup=72, p<0.01, \\
r=-.65^{*}\end{array}$ \\
\hline & & $\begin{array}{l}\text { C vs NA U }=31.5, p<0.01 \\
r=-.69^{*}\end{array}$ \\
\hline & & $A$ vs $N A U=107, n s, r=-.15$ \\
\hline \multirow[t]{3}{*}{ Surprise } & \multirow{3}{*}{$\begin{array}{l}H(2)=6.69 \\
p<0.05\end{array}$} & $C$ vs $A U=167, n s, r=-.33$ \\
\hline & & $\begin{array}{l}\text { C vs NA U }=107, p<0.01 \\
r=-.32^{*}\end{array}$ \\
\hline & & $A$ vs $N A U=120, n s, r=-.06$ \\
\hline
\end{tabular}

\section{Apathy and social awareness}

Patients with apathy were also significantly impaired on the Social awareness test where they were required to judge a protagonist's behaviour in a story vignette by ascertaining whether an individual had violated socioconventional norms or whether the behavior was normal. The relatively poorer performance by these patients on this test included rating common social behaviours as 'shocking' or 'eccentric' while unusual or inappropriate social behaviours were sometimes judged as normal. Thus the performance of these patients cannot simply be attributed to a response bias or a lower level of response. It is possible that there are emotional contributions to social behaviour judgements akin to those linked to moral judgements, but this has not been established. In the context of autistic spectrum disorders it has been argued that impairments on the Social awareness test reflect reduced processing of the social context of a situation, an inability to take the perspective of the protagonist in the story, or are a result of a rigid application of social rules [73]. We can with some confidence rule out social perspective-taking (ToM) deficits as critical, given that the patients with apathy and those without apathy did not differ in this capacity. Further work is 
required to establish the factors that generate our observed dissociation.

\section{Apathy and theory of mind}

Our results suggest that deficits in ToM may not be enough to account for apathy symptoms. Our results on ToM differ from studies that have reported an association between ToM deficits and related negative symptom spectrum disorders which also include apathy symptoms $[43,86]$. There could be a number of reasons to explain the findings. For instance, there is disagreement about how best to conceptualise ToM processes, ranging from the critical role of belief reasoning [48] to the recognition of mental states such as emotions [87]. Consequently, different sets of ToM tests have been used, sometimes on different clinical samples. Some of the ToM tests also fail to control for the influence of other ancillary processes that are separate to the ToM process but are recruited during task performance, such as executive functioning, comprehension, and memory. The tasks used in this study employed more robust mechanisms to isolate ToM processes from these potential confounding variables (e.g., the need for a participant to inhibit their own self-knowledge).

\section{Apathy and emotion perception}

Patients with high levels of apathy did not differ from those without symptoms of apathy. Compared to normal controls, both patient groups showed significant emotion recognition deficits. One possible reason for this lack of differential performance between the two patient groups could be that the recognition of emotion from facial expressions is dependent on diverse processes, mediated by different brain areas. Damage to any of these areas could produce impairments on emotion recognition tests, for a variety of reasons. For example, according to Adolphs [88], the occipitotemporal, orbitofrontal, and somatosensory cortices, together with the hippocampal formation, hypothalamus, and brainstem all play a significant role in the processes involved in extracting and labelling emotion-related information from facial expressions.

\section{Conclusion}

Our study suggests that patients with brain damage and apathy symptoms can have significant problems knowing what is or is not appropriate social conduct. The social impairments shown by these patients may in part reflect socio-cognitive deficits some of which relate to judging the appropriateness or inappropriateness of behaviour in complex interpersonal settings. The deficits are not linked to depression, impaired executive functions or ToM deficits in those individuals with apathy, but they may relate to particular aspects of apathy symptoms like social withdrawal, incapacity to show event-appropriate behavioural and emotional responses, and a failure to meet social expectations.

This study provides the first attempt to develop a sociocognitive phenotype of apathy symptoms. Such a profile can be of great diagnostic and rehabilitation value $[89,90]$, and is important in improving our understanding of the socio-cognitive correlates of apathy.

\section{Strength and weaknesses}

One main weakness in this study is the lower patient numbers on some of the tests, especially the moral sense test. This might have contributed to inadequate power since non-significant findings on tests such as the Ekman test were often in the expected direction. In other words, there were large differences between healthy controls and patients without apathy on one side and those with apathy on the other. Larger sample sizes might probably have produced more significant results. Future studies may consider using larger samples of patients and also using shorter socio-cognitive tests with less language loading.

\section{Additional files}

Additional file 1: The Moral Sense Test: sample item.

Additional file 2: The SAT test sample item.

\section{Competing interests}

There are no financial or non-financial competing interests on this study.

\section{Authors' contributions}

PN carried out the study, analysed the data and produced the draft. GH and SD improved on the draft and also helped with the recruitment of patients. All authors read and approved the final manuscript.

\section{Acknowledgements}

The research was supported by grants from The University of Birmingham, The University of Cape Town, NHS R \& D Support, the MRC, the Stroke Association, and The Canon Collins Educational Trust for Southern Africa. We thank all the participants who took part in this study.

\section{Author details}

${ }^{1}$ Department of Psychology, University of Cape Town, Rondebosch 7701, South Africa. ${ }^{2}$ School of Psychology, University of Birmingham, Birmingham, UK. ${ }^{3}$ Division of Neurosciences, Imperial College, London, UK.

Received: 1 November 2012 Accepted: 17 January 2014 Published: 23 January 2014

\section{References}

1. Hama S, Yamashita H, Yamawaki S, Yamawaki S, Kurisu K: Post-stroke depression and apathy: Interactions between functional recovery, lesion location, and emotional response. Psychogeriatrics 2011, 11:68-76.

2. Marin RS: Apathy: concept, syndrome, neural mechanisms, and treatment. Semin Clin Neuropsychiatry 1996, 1:304-314

3. Gray JM, Shepherd M, McKinley WW: Negative symptoms in the traumatically brain-injured during the first year post-discharge, and their effect on rehabilitation status, work status and family burden. Clin Rehabil 1994, 8:188-197.

4. Pedersen KF, Larsen JP, Alves G, Aarsland D: Prevalence and clinical correlates of apathy in Parkinson's disease: A community-based study. Parkinsonism Relat Disord 2009, 15:295-299. 
5. Levy ML, Cummings JL, Fairbanks LA, Masterman D, Miller BL, Craig AH, Paulsen JS, Litvan I: Apathy is not depression. J Neuropsychiatry Clin Neurosci 1998, 10:314-319.

6. Sperry SD, StrausS ME, Landes AM: The relation of apathy and depression, cognition and daily function in dementia (abstract). J Int Neuropsychol Soc 2001, 7:190.

7. Kant R, Duffy JD, Pivovarnik A: Prevalence of apathy following head injury. Brain Inj 1998, 12:87-92.

8. Starkstein SE, Fedoroff JP, Price TR, Leiguarda R, Robinson RG: Apathy following cerebrovascular lesions. Stroke 1993, 24:1625-1630.

9. Landes AM, Sperry SD, Strauss ME, Geldmacher DS: Apathy in Alzheimer's disease. J Am Geriatr Soc 2001, 49:1700-1707.

10. Andersson S, Bergedalen AM: Cognitive correlates of apathy in traumatic brain injury. Neuropsychiatry Neuropsychol Behav Neurol 2002, 15:184-191.

11. Finset A, Andersson S: Coping strategies in patients with acquired brain injury: Relationships between coping, apathy, depression and lesion location. Brain Inj 2002, 14:887-905.

12. Kuzis G, Sabe L, Tiberti C, Dorrego F, Starkstein SE: Neuropsychological correlates of apathy and depression in patients with dementia. Neurology 1999, 52:1403-1407.

13. Van Reekum R, Stuss DT, Ostrander L: Apathy: why care? J Neuropsychiatry Clin Neurosci 2005, 17:7-19.

14. Chase TN: Apathy in neuropsychiatric disease: diagnosis, pathophysiology, and treatment. Neurotox Res 2011, 19:266-278.

15. Robert $P$, Onyike CU, Leentjens AFG, Dujardin K, Aalten P, Starkstein S, Verhey FRJ, Yessavage J, Clement JP, Drapier D, Bayle F, Beinot M, Boyer P, Lorca PM, Thibaut F, Gauthier S, Grossberg G, Vellas B, Byrne J: Proposed diagnostic criteria for apathy in Alzheimer's disease and other neuropsychiatric disorders. Euro Psychiatry 2009, 24:98-104.

16. Feil D, Razani J, Boone K, Lesser I: Apathy and cognitive performance in older adults with depression. Int J Geriatr Psychiatry 2003, 18:479-485.

17. Marin RS: Apathy- Who cares? An introduction to apathy and related disorders of diminished motivation. Psychiatric Ann 1997, 27:18-23.

18. Okada K, Kobayashi S, Yamagata S, Takahashi K, Yamaguchi S: Poststroke apathy and regional cerebral blood flow. Stroke 1997, 28:2437-2441.

19. Brown RG, Pluck G: Negative symptoms: the 'pathology' of motivation and goal-directed behaviour. Trends Neurosci 2000, 23:412-417.

20. Peters F, Perani D, Herholz K, Beuthien-Baumann B, Sorbi S, Pupi A, Degueldre C, Lemaire C, Collette F, Salmon E: Orbitofrontal dysfunction related to both apathy and disinhibition in frontotemporal dementia. Dement Geriatr Cogn Disord 2006, 21:373-379.

21. Levy R, Dubois B: Apathy and the functional anatomy of the prefrontal cortex-basal ganglia circuits. Cereb Cortex 2006, 16:916-928.

22. Lane-Brown AT, Tate RL: Apathy after traumatic brain injury: an overview of the current state of play. Brain Impairment 2011, 12:43-53.

23. Onoda K, Kuroda $Y$, Yamamoto $Y$, Abe $S$, Oguro H, Nagai A, Bokura H, Yamaguchi S: Post-stroke apathy and hypoperfusion in basal ganglia: SPECT study. Cerebrovasc Dis 2011, 31:6-11.

24. Thobois $\mathrm{S}$, Ardouin $\mathrm{C}$, Lhommee $\mathrm{E}$, Klinger $\mathrm{H}$, Lagrange $\mathrm{C}$, Xie J, Fraix V, Coelho Braga MC, Hassani R, Kistner A, Juphard A, Seigneuret E, Chabardes S, Mertens P, Polo G, Reilhac A, Costes N, LeBars D, Savasta M, Tremblay L, Quesada JL, Bosson JL, Benabid AL, Broussolle E, Pollak P, Krack P: Non-motor dopamine withdrawal syndrome after surgery for Parkinson's disease: predictors and underlying mesolimbic denervation. Brain 2010, 133(4):1111-1127.

25. Tunnard C, Whitehead D, Hurt C, Wahlund LO, Mecocci P, Tsolaki M, Vellas B, Spenger C, Kłoszewska I, Soininen H, Lovestone S, Simmons A: Apathy and cortical atrophy in Alzheimer's disease. Int J Geriatr Psychiatry 2010 26:741-748.

26. Walton ME, Bannerman DM, Alterescu K, Rushworth FS: Functional Specialization within medial frontal cortex of the anterior cingulate for evaluating effort-related decisions. J Neurosci 2003, 23:6475-6479.

27. Critchley HD, Mathias CJ, Josephs O, O'Doherty J, Zanini S, Dewar B, Cipolotti L, Shallice T, Dolan RJ: Human cingulate cortex and autonomic control: converging neuroimaging and clinical evidence. Brain 2003, 126:2139-2152.

28. Laplane D, Degos JD, Baulac M, Gray F: Bilateral infarction of the anterior cingulate gyri and of the fornices. Report of a case. J Neurol Sci 1981, 51:289-300.

29. Lanctot KL, Moosa S, Herrmann N, Leibovitch FS, Rothenburg L, Cotter A Black SE: A SPECT study of apathy in Alzheimer's disease. Dement Geriatr Cogn Disord 2007, 24:65-72.
30. Migneco O, Benoit M, Koulibaly PM, Dygai I, Bertogliati C, Desvignes P, Robert PH, Malandain G, Bussiere F, Darcourt J: Perfusion brain SPECT and statistical parametric mapping analysis indicate that apathy is a cingulate syndrome: a study in Alzheimer's disease and non-demented patients. Neuroimage 2001, 13:896-902.

31. Apostolova LG, Akopyan GG, Partiali N, Steiner CA, Dutton RA, Hayashi KM, Dinov ID, Toga AW, Cummings JL, Thompson PM: Structural correlates of apathy in Alzheimer's disease. Dement Geriatr Cogn Disord 2007, 24:91-97.

32. Massimo L, Powers C, Moore P, Vesely L, Avants B, Gee J, Libon DJ, Grossman M: Neuroanatomy of apathy and disinhibition in frontotemporal lobar degeneration. Dement Geriatr Cogn Disord 2009, 27:96-104.

33. Beer JS, Heerey EH, Keltner D, Scabini D, Knight RT: The regulatory function of self-conscious emotion: Insights from patients with orbitofrontal damage. J Pers Soc Psychol 2003, 85:594-604.

34. Damasio AR: Looking for Spinoza: Joy, Sorrow, and the Feeling Brain. New York: Harcourt; 2003.

35. Camille N, Coricelli G, Sallet J, Pradat-Diehl P, Duhamel JR, Sirigu A: The involvement of the orbitofrontal cortex in the experience of regret. Science 2004, 304:1167-1170.

36. Krajbich I, Adolphs R, Tranel D, Denburg NL, Camerer CF: Economic games quantify diminished sense of guilt in patients with damage to the prefrontal cortex. J Neurosci 2009, 29:2188-2192

37. Frith CD: The Cognitive Neuropsychology of Schizophrenia. Hove, UK: Lawrence Erlbaum Associates; 1992

38. Baron-Cohen S: Mind blindness: an essay on autism and theory of mind. Cambridge (MA): MIT Press; 1995

39. Baron-Cohen S, Jolliffe T, Mortimore C, Robertson M: Another advanced test of theory of mind: Evidence from very high functioning adults with autism or Asperger syndrome. J Child Psychol Psychiatry 1997, 38:813-822.

40. Baron-Cohen S, Leslie AM, Frith U: Does the autistic child have a 'theory of mind'? Cognition 1985, 21:37-46.

41. Rowe AD, Bullock PR, Polkey CE, Morris RG: Theory of mind impairments and their relationship to executive functioning following frontal lobe excisions. Brain 2001, 124:600-616.

42. Stuss DT, Buckle L: Traumatic brain injury: neuropsychological deficits and evaluation at different stages of recovery and in different pathologic subtypes. J Head Trauma Rehabil 1992, 7:40-49.

43. Mazza M, De Risio A, Surian L, Roncone R, Casacchia M: Selective impairments of theory of mind in people with Schizophrenia. Schizophr Res 2001, 47:299-308.

44. Corcoran R, Frith CD: Conversational conduct and the symptoms of schizophrenia. Cogn Neuropsychol 1996, 1:305-318.

45. Doody GA, Goetz M, Johnstone EC, Frith CD, Cunningham ODG: Theory of Mind and psychoses. Psychol Med 1998, 28:397-405.

46. Corcoran R, Mercer G, Frith CD: Schizophrenia, symptomatology and social inference: investigating 'theory of mind' in people with schizophrenia. Schizophr Res 1995, 17:5-13.

47. Drury VM, Robinson EJ, Birchwood M: 'Theory of mind' skills during an acute episode of psychosis and following recovery. Psychol Med 1998, 28:1101-1112

48. Frith CD, Corcoran R: Exploring 'theory of mind' in people with schizophrenia. Psychol Med 1996, 26:521-530.

49. Cuerva AG, Sabe L, Kuzis G, Tiberti C, Dorrego F, Starkstein SE: Theory of mind and pragmatic abilities in dementia. Neuropsychiatry Neuropsychol Behav Neurol 2001, 14:153-158.

50. Gregory C, Lough S, Stone VE, Erzinclioglu S, Martin L, Baron-Cohen S, Hodges J: Theory of mind in frontotemporal dementia and Alzheimer's disease: Theoretical and practical implications. Brain 2002, 125:752-764.

51. Snowden JS, Gibbons ZC, Blackshaw A, Doubleday E, Thompson J, Craufurd D, Foster J, Happe' F, Neary D: Social cognition in frontotemporal dementia and Huntington's disease. Neuropsychologia 2003, 41:688-701.

52. Richell RA, Mitchell DGV, Newman C, Leonard A, Baron-Cohen S, Blair RJR: Theory of mind and psychopathy: Can psychopathic individuals read the 'language of the eyes'? Neuropsychologia 2003, 41:523-526.

53. Kerr N, Dunbar RIM, Bentall R: Theory of mind deficits in bipolar affective disorder. J Affect Disord 2003, 73:253-259.

54. Corcoran R: Theory of Mind in Schizophrenia. In Social Cognition in Schizophrenia. Edited by Penn D, Corrigan P. Washington,DC: APA; 2001.

55. Starkstein SE, Petracca G, Chemerinski E, Kramer J: Syndromic validity of apathy in Alzheimer's disease. Am J Psychiatry 2001, 158:872-877. 
56. Bechara A, Damasio AR, Damasio H, Anderson SW: Insensitivity to future consequences following damage to human prefrontal cortex. Cognition 1994, 50:7-15

57. Bechara A, Damasio H, Damasio AR, Lee GP: Different contributions of the human amygdala and the ventromedial prefrontal cortex to decision-making. J Neurosci 1999, 19:5473-5481.

58. Bechara A, Tranel D, Damasio H, Damasio AR: An anatomical system subserving decision-making. Soc Neurosci Abstracts 1997, 23:495.

59. Bechara A, Tranel D, Damasio H: Characterization of the decision-making deficit of patients with ventromedial prefrontal cortex lesions. Brain 2002, 123:2189-2202.

60. Tranel D: Emotion, decision-making, and the ventromedial prefrontal cortex. In Principles of frontal lobe function. Edited by Stuss DT, Knight RT. New York: Oxford University Press; 2002:338-353.

61. Koenigs M, Young L, Adolphs R, Tranel D, Cushman F, Hauser M, Damasio A: Damage to the prefrontal cortex increases utilitarian moral judgements. Nature 2007, 446:908-911.

62. Greene J, Haidt J: How (and where) does moral judgement work? Trends Cogn Sci 2002, 6:517-523.

63. Greene JD, Sommerville RB, Nystrom LE, Darley JM, Cohen JD: An fMRI investigation of emotional engagement in moral judgment. Science 2001, 293:2105-2108.

64. Stanton BR, Leigh PN, Howard RJ, Barker GJ, Brown RG: Behavioural and emotional symptoms of apathy are associated with distinct patterns of brain atrophy in neurodegenerative disorders. J Neurol 2013, 260:1-10.

65. Greene JD, Morelli SA, Lowenberg K, Nystrom LE, Cohen JD: Cognitive load selectively interferes with utilitarian moral judgment. Cognition 2008, 107:1144-1154.

66. Marin RS, Biedrzycki RC, Firinciogullari S: Reliability and validity of the Apathy Evaluation Scale. Psychiatry Res 1991, 38:143-162.

67. Shraig A: Apathy and depression scales in Parkinson's disease: Are they good enough? J Neurol Sci 2011, 310:216-219.

68. Beck AT: Beck Depression Inventory. San Antonio, TX: The Psychological Corporation; 1978.

69. Burgess PW, Shallice T: The Hayling and Brixton Tests. Thames Valley Test Company: Thurston, Suffolk; 1997

70. van den Berg E, Nys GM, Brands AM, Ruis C, Van Zandvoort MJ, Kessels RP: The Brixton Spatial Anticipation Test as a test for executive function: Validity in patient groups and norms for older adult. J Int Neuropsychol Soc 2009, 15:695-703.

71. Trenerry MR, Crosson B, DeBoe J, Leber WR: Stroop Neuropsychological Screening Test (SNST). Odessa, Florida: Psychological Assessment Resources; 1989.

72. Kamm FM: Morality, Death and whom to save from it. New York: Oxford University Press; 1998.

73. Dewey M: Living with Asperger's syndrome. In Autism and Asperger syndrome. Edited by Frith U. Cambridge: Cambridge University Press; 1991:184-206.

74. Samson D, Apperly IA, Chiavarino C, Humphreys GW: Left temporoparietal junction is necessary for representing someone else's belief. Nat Neurosci 2004, 7:499-500

75. Samson D, Apperly I, Kathirgamanathan U, Humphreys G: Seeing it my way: A case of a selective deficit in inhibiting self-perspective. Brain 2005, 5:1102-1111.

76. Apperly IA, Samson D, Chiavarino C, Humphreys GW: Tempero parietal lobe contribution to Theory of Mind: Neuropsychological evidence from false belief task with reduced language and executive demands. J Cogn Neurosci 2004, 16:1773-1784.

77. Young A, Perret D, Calder A, Sprengelmeyer R, Ekman P: Facial Expression of Emotion-Stimuli and Tests (FEEST). England: Thames Valley Test Company; 2002.

78. Greene JD, Cushman FA, Stewart LE, Lowenberg K, Nystrom LE, Cohen JD: Pushing moral buttons: The interaction between personal force and intention in moral judgment. Cognition 2009, 111:364-371.

79. Shenhav A, Greene JD: Moral judgments recruit domain-general valuation mechanisms to integrate representations of probability and magnitude. Neuron 2010, 67:667-677

80. Mendez MF, Anderson E, Shapira JS: An investigation of moral judgement in frontotemporal dementia. Cogn Behav Neurol 2005, 18:193-197.
81. Young L, Bechara A, Tranel D, Damasio H, Hauser M, Damasio A: Damage to ventromedial prefrontal cortex impairs judgment of harmful intent. Neuron 2010, 65:845-851

82. Damasio AR, Tranel D, Damasio H: Somatic markers and the guidance of behavior: theory and preliminary testing. In Frontal lobe function and dysfunction. Edited by Levin HS, Eisenberg HM, Benton AL. New York: Oxford UP; 1991:217-229.

83. Cummings JL: On: Frontal-subcortical circuits and human behaviour. J Psychosom Res 1998, 44:627-628.

84. Mega MS, Cummings JL: Frontal-subcortical circuits and neuropsychiatric disorders. J Neuropsychiatry Clin Neurosci 1994, 6:358-370.

85. Moran JM, Young LL, Saxe R, Lee SM, O'Young D, Mavros PL, Gabrieli JD: Impaired theory of mind for moral judgment in high-functioning autism. Proc Natl Acad Sci USA 2011, 108:2688-2692

86. Liddle PF: The symptoms of chronic schizophrenia: a re-examination of the positive-negative dichotomy. Br J Psychiatry 1987, 158:340-345.

87. Njomboro P, Deb S, Humphreys G: Dissociation between Decoding and Reasoning about Mental States in Patients with Theory of Mind Reasoning Impairments. J Cogn Neurosci 2008, 20:1557-1564.

88. Adolphs R: Neural systems for recognizing emotion. Curr Opin Neurobiol 2002, 12:169-177.

89. Horan WP, Kern RS, Penn DL, Green MF: Social cognition training for individuals with schizophrenia: emerging evidence. Am J Psychiatr Rehabil 2009, 107:47-54

90. Brekke JS, Hoe M, Long J, Green MF: How neurocognition and social cognition influence functional change during community based psychosocial rehabilitation for individuals with schizophrenia. Schizophr Bull 2007, 233:1247-1256.

doi:10.1186/1471-2377-14-18

Cite this article as: Njomboro et al:: Exploring social cognition in patients with apathy following acquired brain damage. BMC Neurology 2014 14:18

\section{Submit your next manuscript to BioMed Central and take full advantage of:}

- Convenient online submission

- Thorough peer review

- No space constraints or color figure charges

- Immediate publication on acceptance

- Inclusion in PubMed, CAS, Scopus and Google Scholar

- Research which is freely available for redistribution 